\title{
Leptospirosis: A disease with global prevalence
}

\begin{abstract}
Leptospirosis, a zoonotic disease is prevalent throughout the globe. This condition is enormously increasing and is caused by a spirochete Leptospira. Contaminated fresh water is the major source of the disease. The clinical presentation of Leptospirosis is very vast and ranges from self limited non fatal infection to highly mortal respiratory and renal failure. The Weil's disease associated with severe leptospirosis which is characterizes by jaundice, renal failure and hemorrhage. The condition is so much alarming that clinical suspicion is sufficient for empirical therapy. The gold standard is microscopic agglutination test though serological studies are widely conducted for the diagnostic purpose. The antibiotics use for the treatment of Leptospirosis includes oral doxycycline, azithromycin and penicillins. Among the parenteral therapy Intravenous penicillin $\mathrm{G}$ and third generation cephalosporins are used. We reviewed the clinical presentation, diagnosis, treatment and prevention of leptospirosis in this study.
\end{abstract}

Keywords: Leptospirosis, Spirochete, infectious disease
Volume 6 Issue 5 - 2018

\author{
Muhammad Bilal khattak,' Sheraz Jamal \\ Khan, ${ }^{2}$ Aqeel khan ${ }^{3}$
}

'Assistant Professor, Department of Internal Medicine, Hayatabad Medical Complex, Pakistan

${ }^{2}$ Professor, Department of Internal Medicine, Hayatabad Medical Complex, Pakistan

${ }^{3}$ Assistant Professor, Department of Pediatrics, Hayatabad

Medical Complex, Pakistan

Correspondence: Sheraz Jamal Khan, Professor, Department of Internal Medicine, Hayatabad Medical Complex, Peshawar, Pakistan, Tel 923458590900, Email shiraz.janal@gmail.com

Received: January 24, 2018 | Published: November 28, 2018

\section{Introduction}

Leptospirosis, a zoonotic condition is caused by spirochete Leptospira. The disease presentation is very wide from subclinical to highly mortal multi-organ dysfunction. The recent estimated worldwide incidence of leptospirosis is approximately 1.03 million cases with 58900 associated deaths. ${ }^{1}$ However, this highly endemic global problem has not been identified with facts and reported quite less than its actual prevalence. Several factors are responsible and contributing including subclinical presentation, diagnostic difficulties and under reporting. ${ }^{2}$ The disease prevalence varies from region to region. The disease is several times higher more prevalent in tropical region. Not only high temperature, humidity and rainfall is making the environment favorable for the bug but also close contacts, poor sanitation and rodents presence make it further feasible for disease proliferation as the spirochete is secreted from their renal tubules. ${ }^{3-6}$ Leptospirosis is also prevalent in people who are dealing with water and animals especially farmers and thought be high risk population for this condition. Many cases have been related to water like swimming. ${ }^{7-9}$ The condition has become more rat borne due to expansion of the urban population especially in the developing countries where the expansion is unrestricted and without proper sanitation facilities. ${ }^{10}$ The existence of the disease in non-tropical regions is highly associated with travelling to tropical countries. Therefore globalization and tourism or visits to tropical countries for any reason have generously contributed to the disease burden in countries which are not so favorable in these countries like United Kingdom. ${ }^{11}$ Epidemics of Leptospirosis have been identified especially in disasters and extreme weather. ${ }^{5}$ The emergence of Leptospirosis and countrywide outbreak in Thailand and Sri Lanka are the examples. ${ }^{12,13}$

Out of 19 species of Leptospira 9 are causing the Leptospirosis This bacterial spirochete is corkscrew-shaped with an end hook. These are motile, aerobic and have great affinity for warm and humid environment. Being zoonotic in nature, animals especially rodents are responsible for the environmental contamination and ultimate affecting of the humans. ${ }^{14,15}$ As the Leptospires are readily secreted by the renal tubules of these animals, therefore, either the soil and water is contaminated or direct exposure to the urine of these animals is ultimately causing the disease. The disease is also caused in individuals who are exposed directly to blood the affected animal The
Leptospires after contact to human body through orofecal, respiratory or injured muco-cutaneous tissue enter the body and multiply in the blood. The organisms is distributed to the whole body via blood stream, which may lead to various. ${ }^{16-18}$

\section{Clinical presentation}

The clinical presentation of leptospirosis is varying widely from nonspecific to highly mortal hepatic and renal failure. After an incubation time of 2 to 21 days, the acute phase is usually sudden and characterized by fever, headache and myalgia. Later symptoms may include conjunctival injection, abdominal pain, vomiting, dry cough, loose stools, prostration, icterus, anuria or oliguria, cardiac arrhythmia or deficiency, meningeal syndrome and a skin rash. ${ }^{19}$

The symptoms including pyrexia and muscle pain are not that severe initially and last from few days to few weeks. But the headache is at times so intense that the response is even poor to analgesics. Aseptic meningitis is seen $\mathrm{n}$ in almost fifty percent of cases. Even cranial nerves involvement and encephalitis is observed. Psychological features ranges from delirium in acute severe cases to dementia. ${ }^{20}$ The Gastrointestinal and liver involvement is also frequent with Leptospirosis. In case of aculculous cholecystitis Murphy's sign is positive. ${ }^{21,22}$ The ophalmogical features may be seen as early as during initial days to as late as a year with persistence for years. Conjunctival injection is found frequently. Uveitis is the prime feature and includes both iridocyclitis or/and chorioretinitis..$^{23}$ The patient can present with hypo-volumic features, hematuria, oliguria and even anuria. The most severe and mortal feature is Weil syndrome, which manifests as deep yellow discoloration (fulminant hepatitis) with severe hepatic necrosis and severe renal dysfunction. Pulmonary manifestations include cough, dyspnea, chest pain, bloodstained sputum, hemoptysis, and respiratory failure. The respiratory system involvement is carrying high mortality even as high as $50 \%-70 \% .^{24}$ The cardiac manifestations of the Leptospira infection include myocarditis, pericarditis, heart block and arrhythmias. ${ }^{25}$

\section{Diagnostic testing}

The hematological work up includes leukocytosis, thrombocytopenia, elevated CRP and ESR. Renal and hepatic functions derangement occurs in renal and liver involvement 
respectively. Pus cells and protein and few red blood cells can be seen on urinalysis. Cerebrospinal fluid will give picture of aseptic meningitis. ${ }^{14,26}$ Definitive diagnosis is by visualizing the spirochete by Darkfield microscopy and culture. ${ }^{15,27}$ Culture of blood and CSF is useful during first ten days of the disease and organism takes 1-4 weeks for growth. ${ }^{15}$ Blood and CSF cultures are most useful during the first 10 day of illness (leptospiremic phase), when organisms are spreading hematogenously. ${ }^{16,26}$ During the immune phase of the illness blood culture is not that useful rather urine culture is important as the organism is secreted in the urine. However, as the immune phase begins, yield of blood cultures decreases significantly. Serological test are the most frequently used test to confirm the spirochete and no doubt the "Gold Standard" is the microscopic agglutination test (MAT). Enzyme Linked Immunosorbent Assay (ELISA) is use to detect IgM during initial days of the disease. Conventional and RealTime PCR are far sensitive in early days of the disease and during the therapeutic phase as it detects the nucleic acid and complete organism is not necessary. ${ }^{28,29}$

\section{Treatment}

Mild cases of Leptospirosis are self limited and oral antibiotics including azithromycin, doxycycline, ampillicin and amoxicillin are all treatment options depending upon sensitivity and the disease symptoms respond well. Doxycycline should be avoided in pregnancy and young children. ${ }^{30,31}$ In severe cases Intravenous Penicillin G is very effective. ${ }^{32,33}$ Penicillin $G$ has been found equally effective as cefotaxime and ceftriaxone. ${ }^{32}$ Due to the immune process and phase involved in leptospirosis meta analysis has proved the efficacy and importance of the role of steroids in the early phase of the disease. ${ }^{34}$

\section{Prevention}

A study was conducted over 940 soldiers in the United States. In this double blind randomized study soldiers were randomly assigned into oral Doxycycline $200 \mathrm{mg}$ weekly prophylaxis and a placebo group. As a result 20 patients with placebo and one patient in the oral doxycycline group were found to have leptospirosis. ${ }^{35}$ The results of a cochrane review not in favor of chemoprophylaxis. ${ }^{36}$

\section{Conclusion}

Leptospirosis is a zoonotic disease caused by Leptospira and is globally prevalent. The clinical presentation ranges from mild to severe form with hepato-renal fatal damage. The gold standard is microscopic agglutination test. The diagnosis is confirmed by direct visualization of the organism and positive culture. PCR gives best result during all phases of the diseases. For milder diagnosed cases oral azithromycin, doxycycline, ampicillin and amoxycycline should be used. Parenteral Penicillin G and third generation cephalosporin are extremely effective in severe cases. Chemoprophylaxis is beyond discussion on the basis of current available study.

\section{Acknowledgments}

None.

\section{Conflicts of interest}

Authors declare that there is no conflicts of interest.

\section{References}

1. Costa F, Hagan JE, Calcagno J, et al. Global Morbidity and Mortality of Leptospirosis: A Systematic Review. PLoS Negl Trop Dis. 2015;9(9):e0003898.
2. Bharti AR, Nally JE, Ricaldi JN, et al. Leptospirosis: a zoonotic disease of global importance. Lancet Infect Dis. 2003;3(12):757-771.

3. Levett PN. Leptospirosis. Clinical Mirobiol Rev. 2001;14(2):296-326.

4. Hartskeerl RA, Collares-Pereira M, Ellis WA. Emergence, control and re-emerging leptospirosis: dynamics of infection in the changing world. Clin Microbiol Infect. 2011;17(4):494-501.

5. Leshem E, Meltzer E, Schwartz E. Travel-associated zoonotic bacterial diseases. Curr Opin Infect Dis. 2011;24(5):457-463.

6. Pappa G, Papadimitrious P, Siozopoulou V, et al. The globalization of leptospirosis: fueling the fire. Ind J Infect Dis. 2008;12:351-357.

7. Adler B, de La Pena Moctezuma A. Leptospiral and leptospirosis. Vet Microbiol. 2010;140(3-4):287-296.

8. Katz AR, Ansdell VE, Effler PV, et al. Leptospirosis in Hawaii, 19741998: epidemiologic analysis of 353 laboratory-confirmed cases. Am J Trop Med Hyg. 2002;66(1):61-70.

9. Sejvar J, Bancroft E, Winthrp K, et al. Leptospirosis in "Eco-Challenge” athletes, Malaysian Borneo, 2000. Emerg Infect Dis. 2003;9(6):702-707.

10. Amilasan A, Ujiie M, Suzuki M, et al. Outbreak of Leptospirosis after Flood, the Philippines, 2009. Emerg Infect Dis. 2012;18(1):91-94.

11. Johnston V, Stockley JM, Dockrell D, et al. Fever in returned travelers presenting in the United Kingdom: recommendations for investigation and initial management. $J$ Infect. 2009;59(1):1-18.

12. Wuthiekanun V, Sirisukkarn N, Daengsupa P, et al. Clinical diagnosis a demographic distribution of leptospirosis, Thailand. Emerg Infect Dis. 2007;13(1):124-126.

13. Agampodi S, Peacock SJ, Thevanesa V. The potential emergence of leptospirosis in Sri Lanka. Lancet Infect Dis. 2009;9(9):524-526.

14. Haake DA, Levett PN. Leptospira Species (Leptospirosis). In: Bennett JE, Dolin R, Blaser JM, editors. Mandell, Douglas, and Bennett's Principles and Practice of Infectious Diseases. 8th ed. Philadelphia, PA: Saunders; 2015.

15. Schreier S, Doungchawee G, Chadsuthi S, et al. Leptospirosis: current situation and trends of specific laboratory tests. Expert Rev Clin Immunol. 2013;9(3):263-280.

16. Haake DA, Levett PN. Leptospirosis in humans. Curr Top Microbiol Immunol. 2015;387:65-97.

17. Abdulkader RC. Acute renal failure in leptospirosis. Ren Fail. 1997;19(2):191-198.

18. Helmerhorst HJ, van Tol EN, Tuinman PR, et al. Severe pulmonary manifestation of leptospirosis. Neth J Med. 2012;70(5):215-221.

19. Dunay S, Bass J, Stremick J. Leptospirosis: a Global Health Burden in Review. Emerg Med. 2016;6:336.

20. El Bouazzaoui A, Houari N, Arika A, et al. Facial palsy associated with leptospirosis. Eur Ann Otorhinolaryngol Head Neck Dis. 2011;128(5):275-277.

21. Peter G, Narasimha H. Acalculous cholecystitis: a rare presentation of leptospirosis progressing to Weil's disease. Asian Pac J Trop Med. 2011;4(12):1007-1008.

22. Person DA, Burnett MW. Leptospirosis. Tripler Army Medical Center. Medical Surveillance Monthly Report. 1996;2:7-10.

23. Pappachan JM, Mathew S, Thomas B, et al. The incidence and clinical characteristics of the immune phase eye disease in treated cases of human leptospirosis. Indian J Med Sci. 2007;61(8):441-447.

24. Segura ER, Ganoza CA, Campos K, et al. Clinical spectrum of pulmonary involvement in leptospirosis in a region of endemic city, with quantification of leptospiral burden. Clin Infect Dis. 2005;40(3):343-351. 
25. Navinan MR, Rajapakse S. Cardiac involvement in leptospirosis. Trans $R$ Soc Trop Med Hyg. 2012;106(9):515-520.

26. Human leptospirosis: guidance for diagnosis, surveillance, and control. Switzerland: WHO; 2003.

27. Vijayachari P, Sugunan AP, Umapathi T, et al. Evaluation of darkground microscopy as a rapid diagnostic procedure in leptospirosis. Indian J Med Res. 2001;114:54-58.

28. Vasconcellos FA, Coutinho ML, da Silva EF, et al. Testing different antigen capture ELISA formats for detection of Leptospira spp. in human blood serum. Trans R Soc Trop Med Hyg. 2010;104(4):259-264.

29. Ahmed A, Grobusch MP, Klatser P, et al. Molecular approaches in the detection and characterization of Leptospira. J Bacteriol Parasitol. $2011 ;(3): 133$.

30. Griffith ME, Hospenthal DR, Murray CK. Antimicrobial therapy of leptospirosis. Curr Opin Infect Dis. 2006;19(6):533-537.
31. Brett-Major DM, Coldren R. Antibiotics for leptospirosis. Cochrane Database Syst Rev. 2012;2:CD008264.

32. Watt G, Padre LP, Tuazon ML, et al. Placebo-controlled trial of intravenous penicillin for severe and late leptospirosis. Lancet. $1988 ; 1(8583): 433-435$

33. Costa E, Lopes AA, Sacramento E, et al. Penicillin at the late stage of leptospirosis: a randomized controlled trial. Rev Inst Med Trop Sao Paulo. 2003;45(3):141-145.

34. Rodrigo C, Lakshitha de Silva N, Goonaratne R, et al. High dose corticosteroids in severe leptospirosis: a systematic review. Trans $R$ Soc Trop Med Hyg. 2014;108(12):743-750.

35. Takafuji ET, Kirkpatrick JW, Miller RN, et al. An efficacy trial of doxycycline chemoprophylaxis against leptospirosis. $N$ Engl $\mathrm{J}$ Med. $1984 ; 310(8): 497-500$.

36. Guidugli F, Castro AA, Atallah AN. Antibiotics for preventing leptospirosis. Cochrane Database Syst Rev. 2000;4:CD001305. 